\title{
From present to the past: The different way of thinking about conservation (A case from design idea for Siola Building, Surabaya)
}

\author{
Defry Agatha Ardianta ${ }^{\mathrm{a}, \mathrm{b}^{*}}$, Bambang Soemardiono ${ }^{\mathrm{a}}$, Tiara Kartika Rini ${ }^{\mathrm{b}}$ \\ ${ }^{a}$ Institut Teknologi Sepuluh Nopember, Kampus ITS Sukolilo, Surabaya 60111, Jawa Timur \\ ${ }^{b}$ ORDES arsitektur, Jl. Penjaringan Timur IV No. 13, Surabaya, Indonesia \\ *Corresponding author. +628155500347 \\ E-mail address: agathadefry@gmail.com
}

\begin{abstract}
The relation between architecture and the era is always arguable. There are two conditions which describe this relation, at first architecture as a reflection of an era and architecture reflects the timelessness. The later condition commonly becomes a standard of value to judge the architecture is irrelevant with an era by forgetting the first condition. Siola is experiencing both of conditions. A lot of proposals to 'regain' its golden time by put intention into heroism or historical background are offered. Many of those efforts focus on how to get the building back like its origin and it's to be used. Analysis concentrates on're-functioning' which means not to take the function back as its origin but to give the new role by considering the contemporary context? Nostalgic and Romantic aspect has critically seen as the opportunity to take appropriate manner toward better improvement of urban living quality. Siola itself is a landmark which escalating the socio-cultural and economic in Tunjungan corridor. According to historical timeline, many functions are implemented in Siola building before. This historical fact leads the vision that function is changeable within less-changing physical appearance. Furthermore, the main task is to encourage the spirit of people by design strategy and to put it within the building. To trigger the spirit of people evoke the spirit of place.
\end{abstract}

Keywords: conservation; re-functioning; context

\section{Introduction}

Siola Building is a shopping centre which one of the silent witness of Surabaya's history. In 1923, Siola was formerly named as Whiteway Laidlaw, a chain of grocery shops that had existed in many countries and possessed by a conglomerate from England. During its functioning time, Siola's ownership had been transferred for several times, although it's main function remained unchanged. In 1940's, the building was taken over by the Japanese and the name was changed to Toko Chiyoda. Later in 1964, Toko Chiyoda was purchased by a group of entrepreneurs, Soemitro, Ing Wibisono, Ong Liem, and Aang, who had collaborated to restart the shopping centre as Siola Shopping Centre. However, the popularity of its existence has been progressively lowered by the emergence of modern shopping centres. Ever since 2011, the building's façade has been renovated and transformed into Tunjungan City. The conservation mainly focuses on treating Siola as a monument in order to preserve and to adjust it. 


\subsection{Timefulness in Conservation: Architecture as a sign of an era}

The problem of architecture within an era is the problem of truth and meaning. ${ }^{1}$ Truth and meaning has always been a common issue in the history of architecture. ${ }^{1}$ The term "architecture as a spirit or a sign of an era" is based on the understanding of timeless idea or truth which is presented in a specific or particular moment in objects. Therefore the objects need to be justified or verified with certain meaning in certain period. This belief has inspired the idea of timelessness in the present. Thus in the spirit of an era there will always be an unacknowledged paradox, a discourse of the timelessness through the momentary.

\subsection{Timelessness in Conservation: Architecture as inherent Truth}

Another side is the idea that the timeless truth is just the same as timeless meaning. ${ }^{2}$ In Aristotelian metaphysic; the truth is transcendental and inherent within all of the existences. Therefore it is self evident that the meaning within the object has the quality of timelessness too. Thus there is no such of backward or forward progression. A divinity and a gothic cathedral can be understood as one and unchanged.

\subsection{Concept on Conservation: Refunctioning the Building}

Siola Building itself, in fact, has different meaning minimally in the past to the present. This proves the unrelated bond between the truth and the meaning. Therefore one option of view is that meaning itself is a matter of changeable representation by the subject.

According to this conclusion refunctioning itself is a decision to avoid no meaning or no matter-ness within the building. This avoidance leads several decision which in the task to give the new role of the building into the present context and importance.

\section{Results and Discussion}
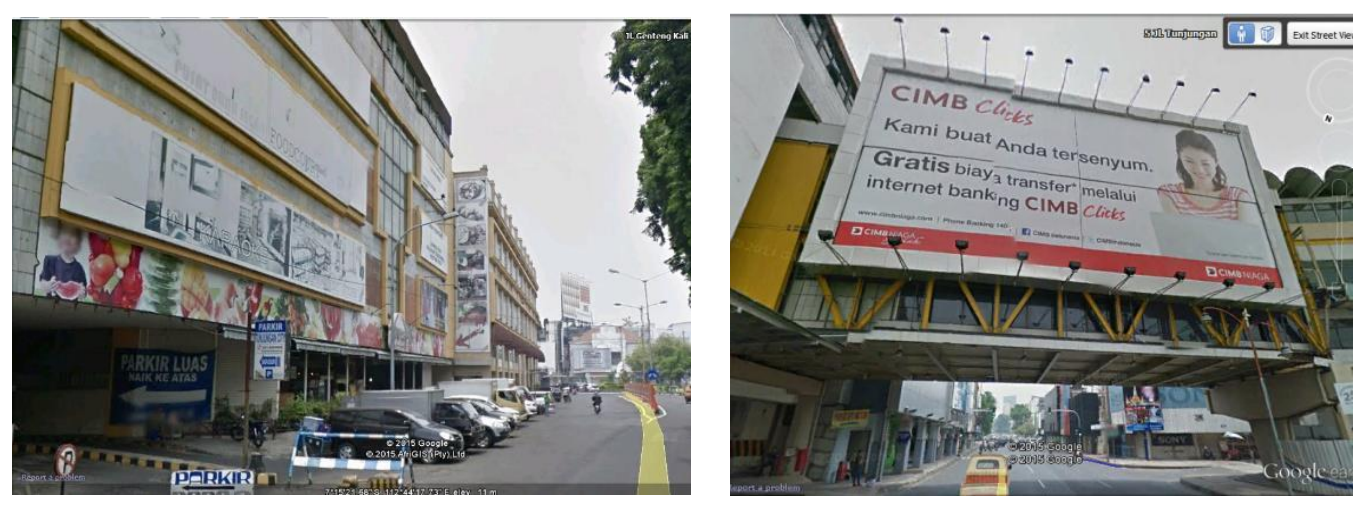

Fig. 2.1 Situation of the surrounding of Siola Building

Jalan Tunjungan has few stores along the pedestrian path. Store - the store generally use glass walls that have transparent properties and facilitate the road users look into the shop and observe things from the outside. Visitors to the transportation mode four-wheel vehicles parked on the shoulder of the road. This leads to a pedestrian street was narrow because it obstructed the vehicle. Contained in Tunjungan Street pedestrian bridge, this bridge becomes the object that is quite interesting because of its scale and position. The bridge has a facade that is covered by a large billboard that less than optimal in appearance.

Siola facade has a repetition of architectural elements such as columns rhythms and pauses between floors. In addition there is additional architectural element that completes the phrase canopy architecture components. It is not 
troubled by the aesthetics, but have problems with the context. Places around the building less comfortable to be passed and that no material has a specific way when juxtaposed with the ornate facade Siola.
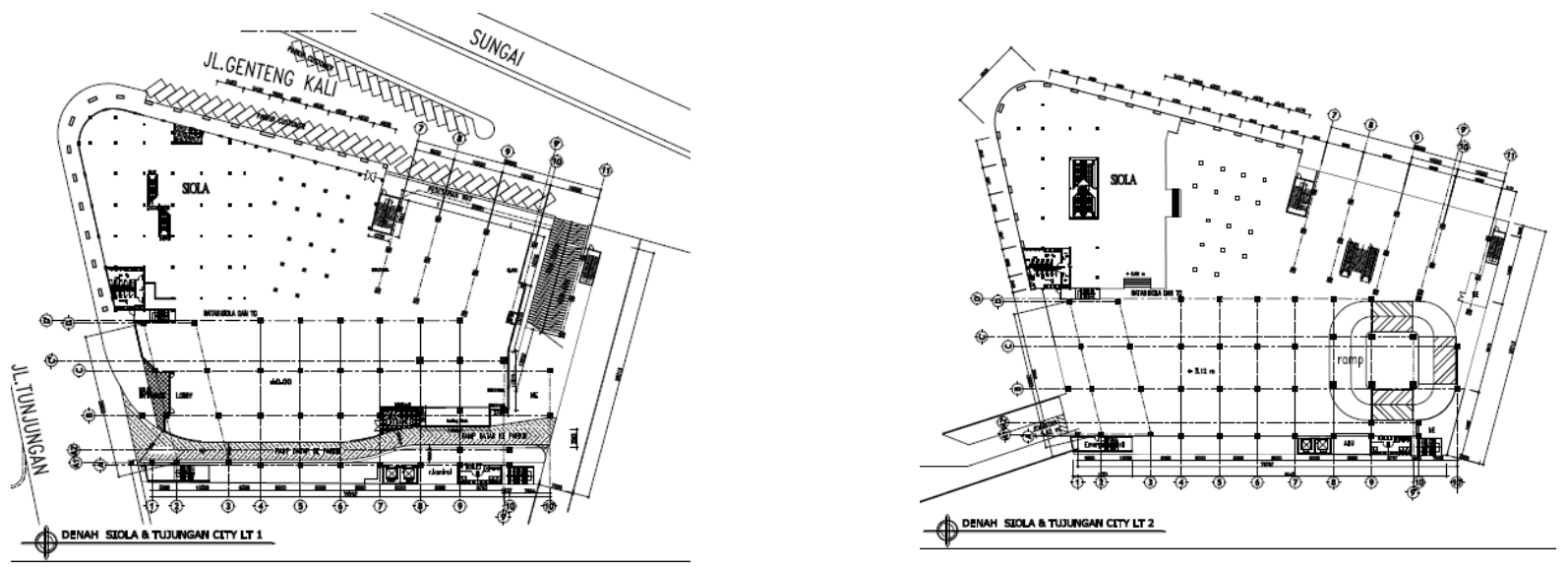

Fig. 2.2 Plan of Siola Bulding

Siola building basically located at the hook that had the opportunity to have two facades on two different paths. Siola facade facing the street shaded by an arcade. This leads to a shaded pedestrian paths where the shade is expected to increase comfort in the building. The Area Planning of Siola on the 1st floor is a culinary center and museum Surabaya. In addition there is a ramp on the side of Jalan Tunjungan for entry into the parking area, it causes side all the way Tunjungan have closed impression. While the side facing Jalan Genteng Kali contained Waiting Room Service and a commercial lease area. On the side facing the road tile facade memorable time more open.

Floor two has a typical layout with floor 1 . Aspects of natural lighting are quite important because there are only openings on the facade. Some attached photos show the quality of the natural lighting on the 2nd floor's room. Natural lighting is pretty good because it can bounce up to the rear of the building. However, it lacks the settlement in the interior so that the interior of the building tend to be monotonous and repetitive.
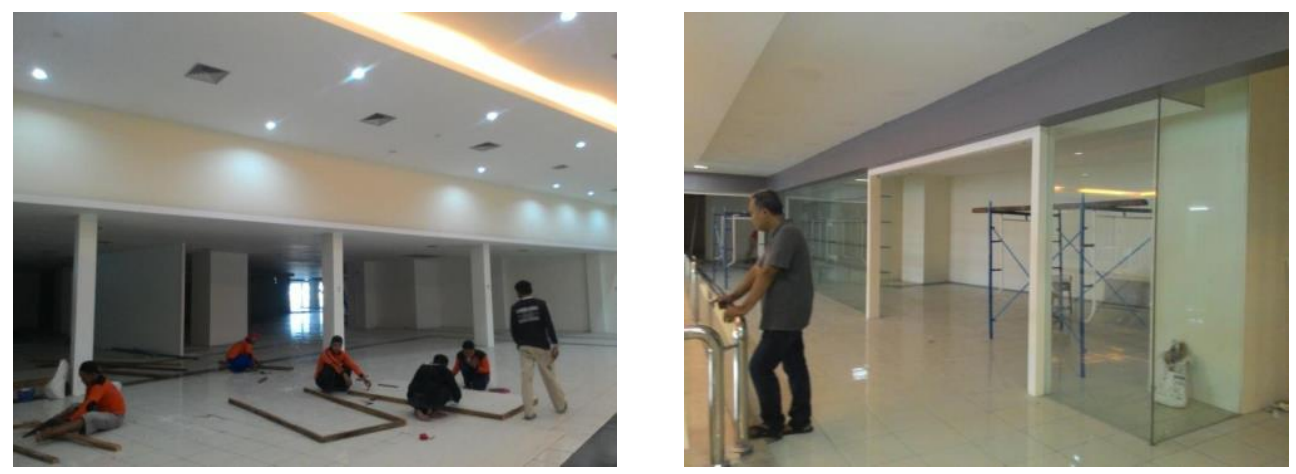

Fig. 2.3 Interior of Siola Building

Therefore it needed replacement or addition of elements that support the aesthetics in the room such as lighting design, painting, or replacing the floor covering material. In some parts of the building has been carried out the replacement material. Some corners for vendor booths have been installed a glass wall to create the atmosphere of the room which is different from other building areas. 


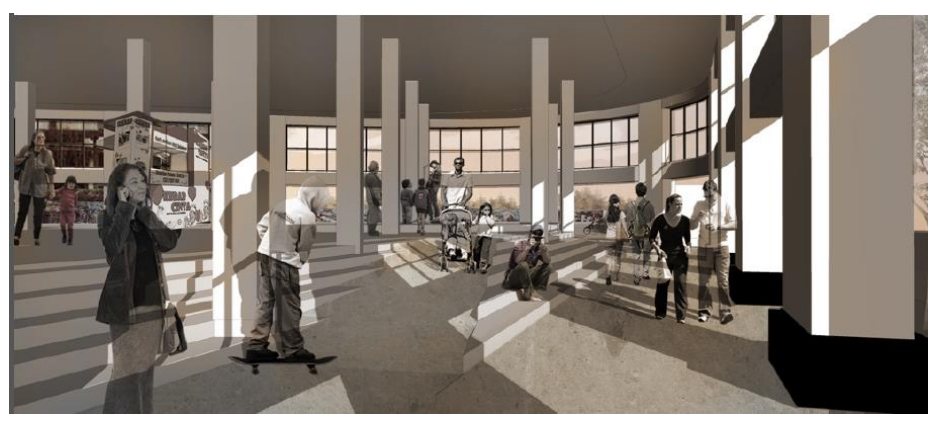

Fig. 2.4 Open Space \& Culinary Centre

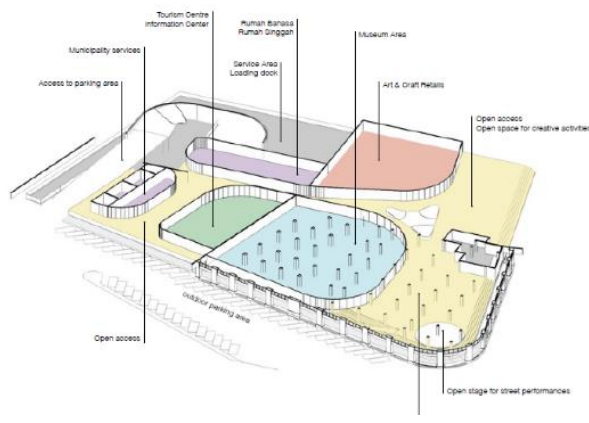

Fig. 2.5 Floor One's zoning

Street life can be seen as street level activity. Therefore accentuating on street level function will enhance the festive of street or the corridor (see Fig. 2.4 \& Fig. 2.5). The main focus of activities directed to recreational, public entertainment, art and gallery. In this case, possibility of user participatory is quite high. The space within the building which is connected to the main street is accessible and open to creative activity. This openness reduces the solid and enclosed of the existing condition.

Other space is used as socio-economic transaction such as art \& craft retail. Siola is well known as commercial or shopping centre. Therefore relevant activity such as transaction can take its importance and justified by the history and shared collective memory of the building. Since Siola is mid rise building, it has the opportunities to have several different aerial views towards streetscape. This opportunity can be seen as, in pragmatic way, selling point of commercial activity. Thus in many interesting points are designed to this activity. Some renovations at façade brings more open to direct sky lightning and also gives chance to nocturnal aesthetic by using certain lightning features.

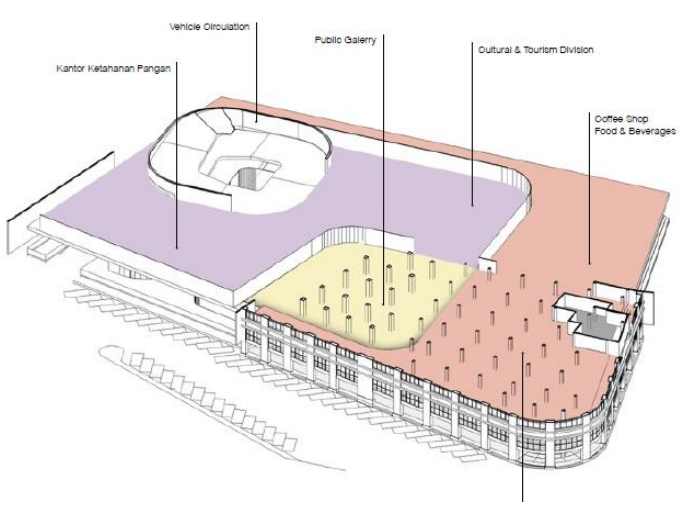

Fig. 2.6 Floor Two's zoning

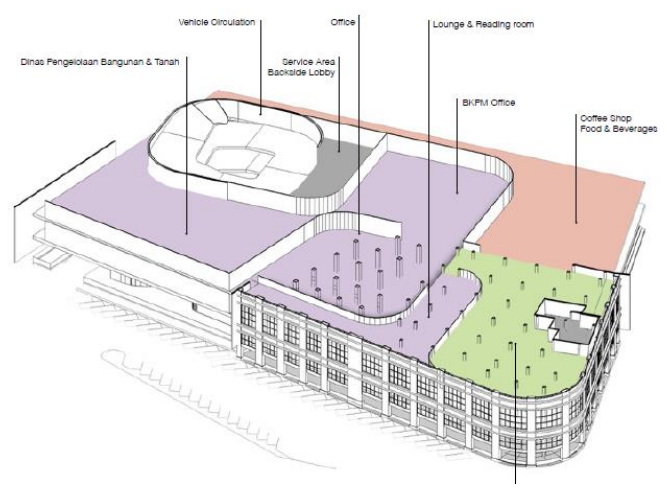

Fig. 2.7 Floor Three's zoning

Surabaya's Government is proposing the main function of the building as an office (see Fig. 2.3 \& Fig. 2.4), in this case public service office. This intension is to put core function and therefore more stable role. This effort can be seen as juxtapositioning the contrast function inside the building. Juxtaposition itself is a technique to gain the nuance, activity, or functional awareness by enclosing the opposite kind of some elements, such as material or activity. It can be understood as the routine over the leisure time or vice versa. The purpose of juxtaposition is to increasing the significance of the activity at one and another time or even at the same time. 


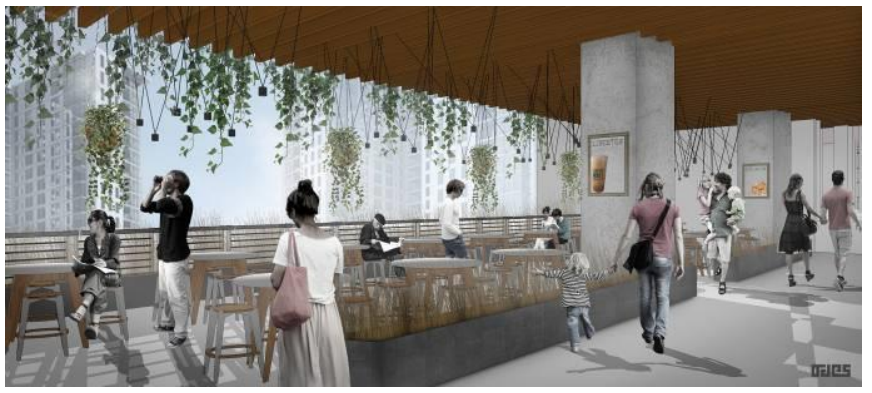

Fig. 2.8 Cafe Area

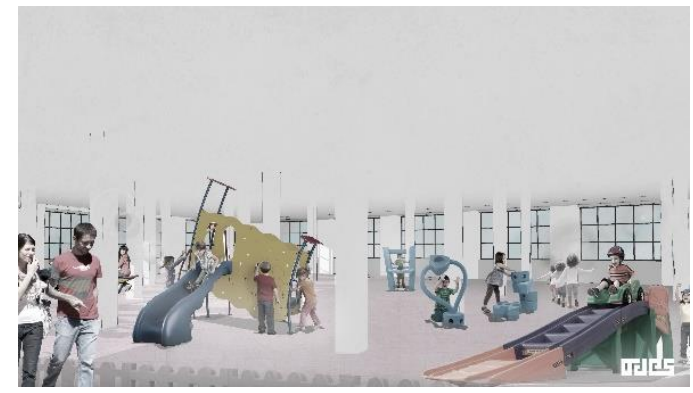

Fig. 2.9 Playground \& Public Space

Figure 2.8 shows the design of Café Area. People can look around the corridor openly and freely. The scene of corridor and city becomes the main attraction. This openness also offers closeness and intimate relation to the users with environment. Column becomes the element of interior which provides artistic potentiality to be explored. Figure 2.9 shows the design of Playground \& Public Space Area. Children can play and sense their place through playing object. This can make better information and introduction of Siola to the youngest generation.

Multifunction \& Exhibition Hall and Rental Room for creative community (see Fig. 2.11), is proposed to give a mutual benefit between government and the public. Beside beneficial in profit, it's also gives the chance to strengthening the sense of belonging towards this building. Areas which close to the window are functioned as food $\&$ beverage restaurant or coffee shop. Slow paced time consuming will create more attentiveness of the user. This attention will relate with its surrounding such as the window. The window brings visual connectivity. This visual connectivity to the main street has enabled through the proposed opening or window. This visual connectivity let the moment on the street is observed ${ }^{4}$. This visual interaction later can possibly reveal the memories of the past of Tunjungan corridor, nostalgic feeling.

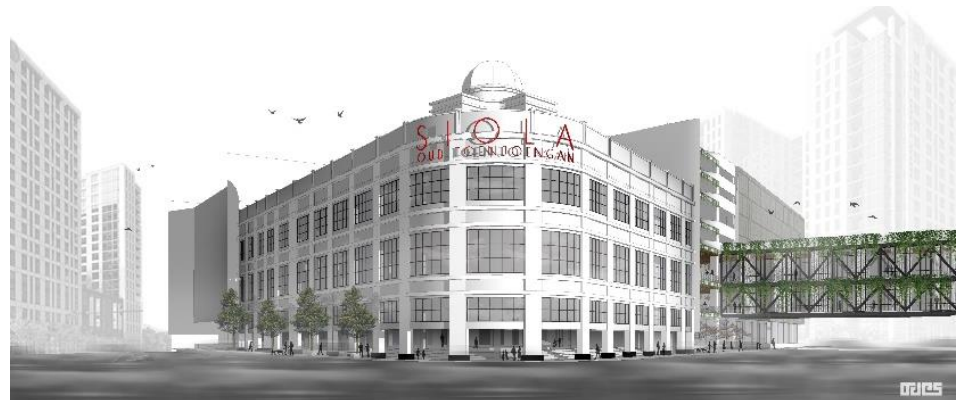

Fig. 2.10 Façade of Siola

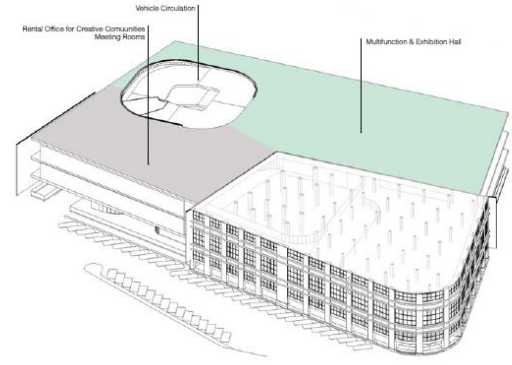

Fig. 2.11 Floor Four's zoning

\subsection{Tunjungan Corridor and its Landmark}

Landmark is essentially help people to build better cognitive or mental map of certain environment. More obscure its vision in one's vision more effortless to construct cognitive map. Cognitive map itself can give some cues to people to have relevant act or response toward environment. Siola, as it has been intended, is a kind of landmark to excel one's recognisablity of Tunjungan corridor. ${ }^{3}$

Tunjungan corridor is dominantly occupied by retail or business activity. Many streets' furniture is carefully designed for this purpose. The width of pedestrian way, its arcade as shelter, and details in façade of shops is purposed 
to conform the passenger and buyer. The street furniture itself has the possibility to be added more value such as relaxation, creative, or participatory purpose. And then proposed design for Siola can keep balancing with its surrounding.

\subsection{Festive, Activity, and Spirit of Place}

Spirit of place has tangible and intangible elements. Tangible elements is in physical matter or object while intangible elements is a kind of abstract such as memory, events, or festival. Festive is collective excitement towards an event. An event can be publicly showed to the public spectators. This event within this building activates the response of the people, help people to retrieve their cognitive map of the circumstances. In certain level the retrieval can recall the intangible elements of spirit of place.

\section{Conclusion}

Function is changeables within less-changing physical appearance. Physical appearance caused by material endurance, therefore minimally function itself preserved by physicality. In Siola's case material endurance relatively last longer than the presence of event. Event contains activity which is responding to context. As context is changed, intentionally or naturally, the activity is also changed. Function, in this sense, consequently is changed.

Understanding and observing context become key action to determine point of view and design method. Design method is triggered by some premises on context like Tunjungan corridor current condition, the potentiality of Siola building, habit of Surabaya's society, and the importance of novel public space. These premises later articulated on design process while still considering the government's proposal to put Siola's building as public service's office.

Discussing on this project mainly focused on its position as landmark, the capacity of building as public space and public event container ${ }^{5}$, so it can gain the festive nuance of the event. This project finally can be a tangible element to recall memory and to present the spirit of place to its place.

\section{References}

Use the "Insert Citation" button to add citations to this document. 